\title{
THE EFFECT OF ANEMIA AND POLYCYTHEMIA ON DIGITAL INTRAVASCULAR BLOOD VISCOSITY ${ }^{1}$
}

\author{
By MILTON MENDLOWITZ \\ (From the Medical Service of Dr. George Baehr, The Mount Sinai Hospital, New York City)
}

(Received for publication February 26, 1948)

Viscosity is a fundamental property of matter, and its mathematical analysis has challenged numerous physicists, including Newton (1) and Einstein (2). It is not our purpose to review the mathematical formulas evolved for the determination of viscosity, but rather to attempt to apply existing principles as simply as possible to a study of the human circulation.

The physical forces involved in any study of intravascular viscosity must always begin with the law elaborated by Poiseuille (3). Most viscometers measure the flow of fluid at a given pressure through a tube of a definite length and diameter, and are based on Poiseuille's law. Viscometers dependent on other principles $(4,5)$ are less analogous to conditions which prevail in any study of intravascular viscosity. The Ostwald (6) and the Hess (7) type of viscometer have hence been most commonly employed for studying the viscosity of blood in vitro. In the former, the velocity of the blood flowing through the tube is low. Hess (8) showed that when the velocity is increased the viscosity decreases, but that within certain optimum ranges of velocity there is little if any change in the viscosity. These optimum velocities are of the order usually found under physiological conditions. At higher velocities flow becomes turbulent, and the relations between pressure, flow, tube diameter and velocity again change (9). Since physiological velocities and those employed in viscometers are such that flow is streamlined, turbulence may be disregarded.

It has also been shown that the viscosity of a fluid decreases as its temperature rises (10). This is believed to be due in part to changes in the volume of the fluid with increasing temperature (10) and in part to other factors (11). In addition, very viscous fluids do not flow at all below a certain minimum pressure (12). This intercept of the pressure-flow ratio line on the pres-

1 Aided by grants from the Dazian Foundation and the American Medical Association Research Fund. sure coördinate is referred to by Bingham and Roepke (13) as the "yield value." These authors therefore suggest that only the fluidity, which is the reciprocal of the viscosity, be used as a measure of the flow characteristics of a fluid, and that all fluidities be corrected for the temperature factor, arbitrarily designating $20^{\circ} \mathrm{C}$. as the point of reference for comparative measurements. Since all viscosities or fluidities are thus relative to water at $20^{\circ} \mathrm{C}$., the terms "relative" or "specific" fluidity or viscosity have been used (5) to indicate this.

In studies of the effect of tube diameter on the viscosity of blood Fåhraeus (14), and later Suter (15) found that below a certain critical diameter the viscosity of blood did not follow the law of Poiseuille, but decreased with decreasing diameters. Fåhraeus explained this by pointing out that in capillary tubes the cells are crowded toward the center of the stream because of their greater weight leaving a comparatively larger peripheral zone of plasma where the greater frictional stresses occur. Since it was thus clear that the viscosity of the blood could change with variations in velocity on the one hand, and tube diameter on the other, the terms "apparent" (12) or "apparent specific" (5) viscosity or fluidity were used to indicate that such measurements were not absolute but were only applicable to the particular system in which the viscosity was studied.

In the more recent modifications of the Poiseuille formula (9) the variables are pressure, volume flow, density, length of tube, radius of tube, mean velocity and viscosity. If the length and cross-sectional area of a viscometer remain constant and the mean velocity is within such a range as to produce a constant effect, these factors taken together-namely, length, cross-sectional area, and velocity-may be considered a single constant. The pressure-flow relationship at a given temperature and density will hence be linear in a viscometer in which all other factors 
become a constant (12). If the only factor changed in such a system is the viscosity of the flowing liquid then the change in frictional resistance to flow with varying viscosity becomes expressed by a change in the slope of the pressureflow line (12). If the intercept of the pressureflow line or "yield value" were zero, the relationship $\frac{P}{F} K$ would accurately reflect changes in viscosity, where $P=$ the pressure in $\mathrm{mm}$. of $\mathrm{Hg}$, $F=$ the flow in $\mathrm{gm}$. per unit of tissue per minute

and $\quad K=\mathrm{a}$ constant.

When the line intercepts the pressure coördinate above zero, as it does with viscous fluids, $\frac{P-P_{1}}{F} K$ now represents the viscosity where $P_{1}$ is the intercept or "yield value."

In 1933 Whittaker and Winton (12) realized that the variable factors in viscosity measurements made it impossible to draw accurate conclusions as to the behavior of fluids in blood vessels from in vitro viscometer studies. They therefore used the hind-limb of a dog to study pressure-flow relationships directly and to determine the effect of changes in viscosity on these relationships. Maximal vasodilatation and stabilization of vasomotor tone were effected by the addition of chloral hydrate to the perfusing blood. In their favorable experiments the pressure-flow relationship was linear. They established the magnitude of the intercept which varied from 7 $\mathrm{mm}$. for plasma to $27 \mathrm{~mm}$. for blood containing $83 \%$ by volume of cells. They found intravascular blood viscosity to be lower than viscometer measurements, as might be expected from Fåhraeus' observations (14). They also found that the viscosity increased very gradually with increasing erythrocyte concentrations at anemic levels and more precipitously at polycythemic levels.

In 1938 (16) a method was developed for measuring blood flow and blood pressure in the fingertip after stabilization of the circulation by indirect heating. The normal range of values was narrower than for any other such clinical method for measuring blood flow. This method was adapted in 1942 (17) to the measurement of peripheral resistance, a crude value representing merely the ratio of pressure to flow multiplied by a constant. Since the velocity factor can be assumed to be relatively constant under these conditions it follows that the pressure-flow ratio expresses changes in the viscosity if the cross-sectional area factor remains unchanged. The cross-sectional area was kept constant by releasing sympathetic tone by indirect heating (16) in each observation. Since the pressure-flow relationship is linear under these conditions, changes in viscosity could be determined by a change in the ratio of pressure to flow, however the individual values for each of these were altered. There was, however, no feasible method for the determination of the magnitude of the pressure intercept in the human digital circulation. For that reason Whittaker and Winton's intercepts (12) were substituted in the hope that the error of such a step would be sufficiently small to enable pressure-flow relationships to be considered linear.

Digital arterial diastolic and systolic pressures were determined by a Gaertner capsule $(16,18)$. The arithmetic mean pressure was considered satisfactory despite the minimal error entailed. The intercept for blood of such erythrocyte concentration as prevailed was subtracted from this mean pressure. Venous pressure was considered included in the intercept value.

Flow was measured calorimetrically (19), using the formula

$$
F=\frac{\left(\Delta t_{1}+\Delta t_{2}\right)(m+e)}{s a\left(t_{3}-t_{4}\right)}, \text { in which }
$$

$F=$ the flow in $\mathrm{gm}$. per sq. $\mathrm{cm}$. per min. in the fingertip,

$\Delta t_{1}=$ the rise in temperature per min. in the calorimeter,

$\Delta t_{2}=$ the fall in temperature per min. after the fingertip is removed,

$m=$ the volume in cc. of the water in the calorimeter,

$\boldsymbol{e}=$ the hydrothermic equivalent of the calorimeter and the fingertip,

$s=$ the specific heat of the blood,

$a=$ the area of immersed fingertip in sq. cm.,

$t_{\mathbf{3}}=$ the mouth temperature in degrees $\mathrm{C}$., and $t_{4}=$ the average calorimeter temperature.

The specific heat was originally taken to be 0.9 according to Stewart (20). It was apparent, however, that this constant might change with varying erythrocyte concentrations and that some effort should be made to determine the exact specific heat of plasma and erythrocytes. Direct calorimetric studies of blood (21) revealed the specific heat of plasma to be 0.94 , and of cells 0.77 . It was also possible to predict the specific heat of any mixture of cells and plasma. Using these values for specific heat, the flow levels were corrected accordingly. Normal digital blood flow now became 0.24 to $0.35 \mathrm{gm}$. per sq. cm. per min. Using the arbitrary constant of 0.3 , the normal 
resistance measured in the manner described above now became 52 to 86 units. $F$ is expressed in grams because the numerator of the equation represents gram-calories. To convert to cc. it is necessary to divide by the specific gravity of the blood.

We studied four patients with polycythemia treated by repeated phlebotomy and also two anemic patients. In one patient with aplastic anemia the erythrocyte concentration was brought up to a normal level by transfusions, and in the other with pernicious anemia, by folic acid. Table I lists results obtained in the patients with polycythemia and Table II, in those with anemia. In the final column the changes in resistance with varying erythrocyte concentrations are listed using the resistance of each patient at normal erythrocyte levels (considered unity) as the point of reference. These ratios therefore represent changes in viscosity relative to that of normal blood. Changes in erythrocyte concentration are represented by changes in hematocrit. In some instances, changes in hemoglobin or erythrocyte count per cu. $\mathrm{mm}$. were converted into hematocrit values by the use of Wintrobe's factors (22). It is clear that no one measurement of erythrocyte concentration is entirely satisfactory in this re-

TABLE I

Polycythemia

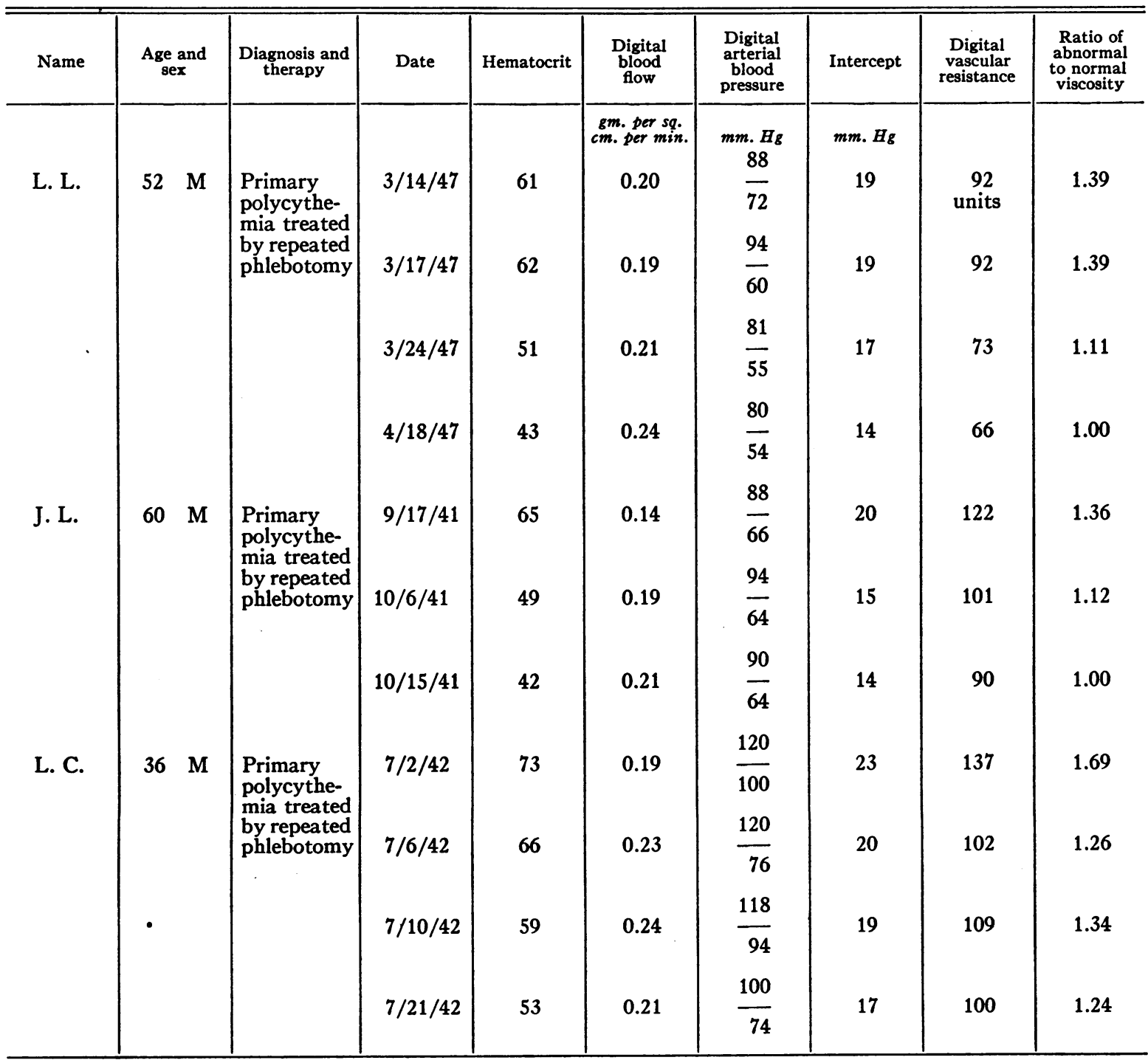


TABLE I-Continued

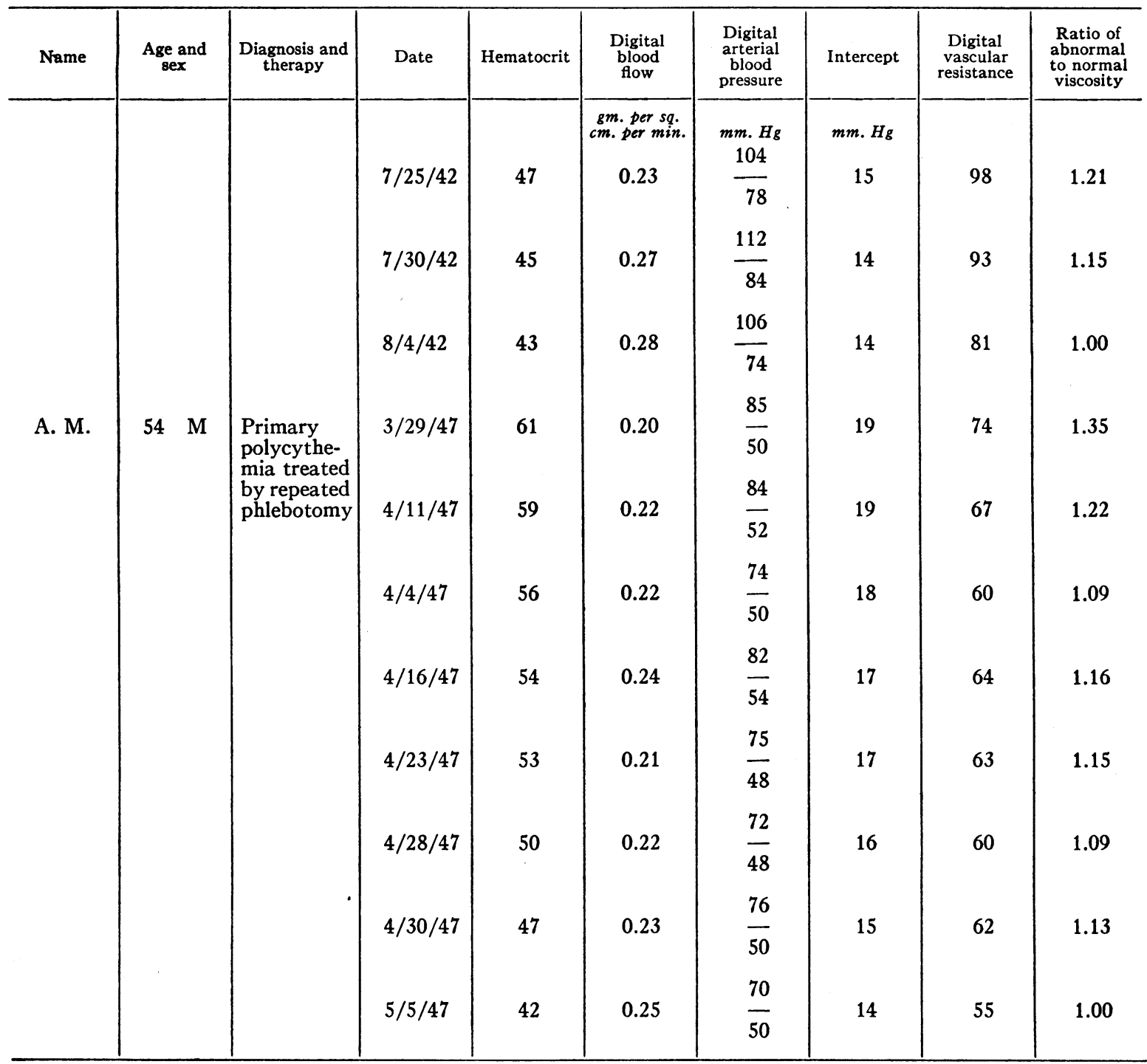

spect. It is well known that in polycythemia the mean corpuscular volume may be small and that it also varies considerably in anemia. Mean corpuscular hemoglobin concentration varies even more (22). Furthermore, there are variations in the hematocrit of capillary, venous and arterial blood (23) and corrections to be made for plasma "trapped" in the cell mass (24). It was our purpose, however, to determine if any change at all could be demonstrated and to approximate the magnitude of the change in the living human subject. It can be seen from Table II that the decrease in viscosity in anemia was small. In polycythemia, the viscosity increased at first slowly with increasing cell concentrations and then precipitously. The increased viscosity produced a decrease in flow in polycythemia and little change in blood pressure, whereas in anemia the relationship between flow and pressure with increasing cell concentrations was variable. In Figure 1 the ratio of normal to abnormal viscosity is plotted against erythrocyte concentration. Whittaker and Winton's (12) curve is drawn in. The observed points correspond well with this curve. One might by extrapolation and assumptions as to the normal blood viscosity convert these figures into fluidities in rhes, or into dynes per sq. cm., but it was felt that this was not justified by the data. 
TABLE II

Anemia

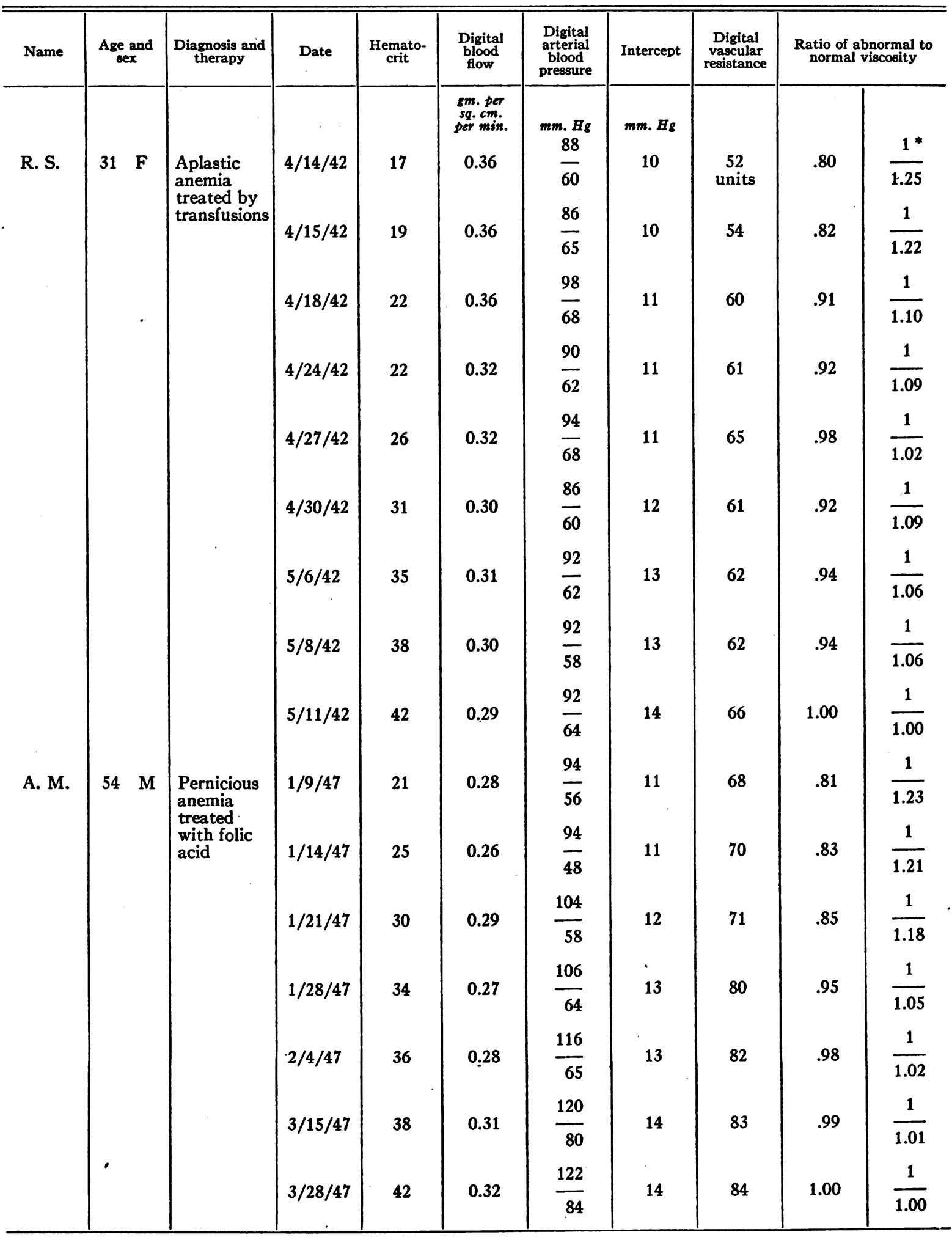

* The ratios are rearranged in this column to correspond with the graph of Whittaker and Winton (12) in order that the points observed in Figure 1 may be compared with the curve obtained by these authors. 
It should be pointed out that the viscosity of the blood has been found to increase with vasoconstriction (25). In flow through capillaries (26) moreover, or through the renal vessels where diffusion is extensive, the changes in viscosity become sufficiently complex to defy mathematical analysis (27). It has already been pointed out that viscosity is influenced by the caliber of the perfused blood vessels, so that the peripheral intravascular blood viscosity may be different from the viscosity of blood flowing through larger vessels or through the heart. The correspondence of the values presented here with those of Whittaker and Winton (12) strongly suggests that we were both measuring corresponding changes in blood viscosity as it affected resistance to flow at given pressures through arteriovenous anastomoses and widely dilated capillaries of living tissues, uninflu- enced by variations in the caliber of the perfused vessels.

\section{SUMMARY AND CONCLUSIONS}

Studies on intravascular blood viscosity in the digital circulation confirm similar studies in animals. They indicate that decreases in erythrocyte concentrations such as are found in anemia decrease the blood viscosity moderately. Increases in erythrocyte concentrations such as are found in polycythemia increase the blood viscosity moderately at lower levels and more steeply at higher levels. At those extremes of anemia and polycythemia which were observed the blood viscosity was found to be $80 \%$ of normal at a hematocrit level of 17 and $169 \%$ of normal at a hematocrit level of 73 .

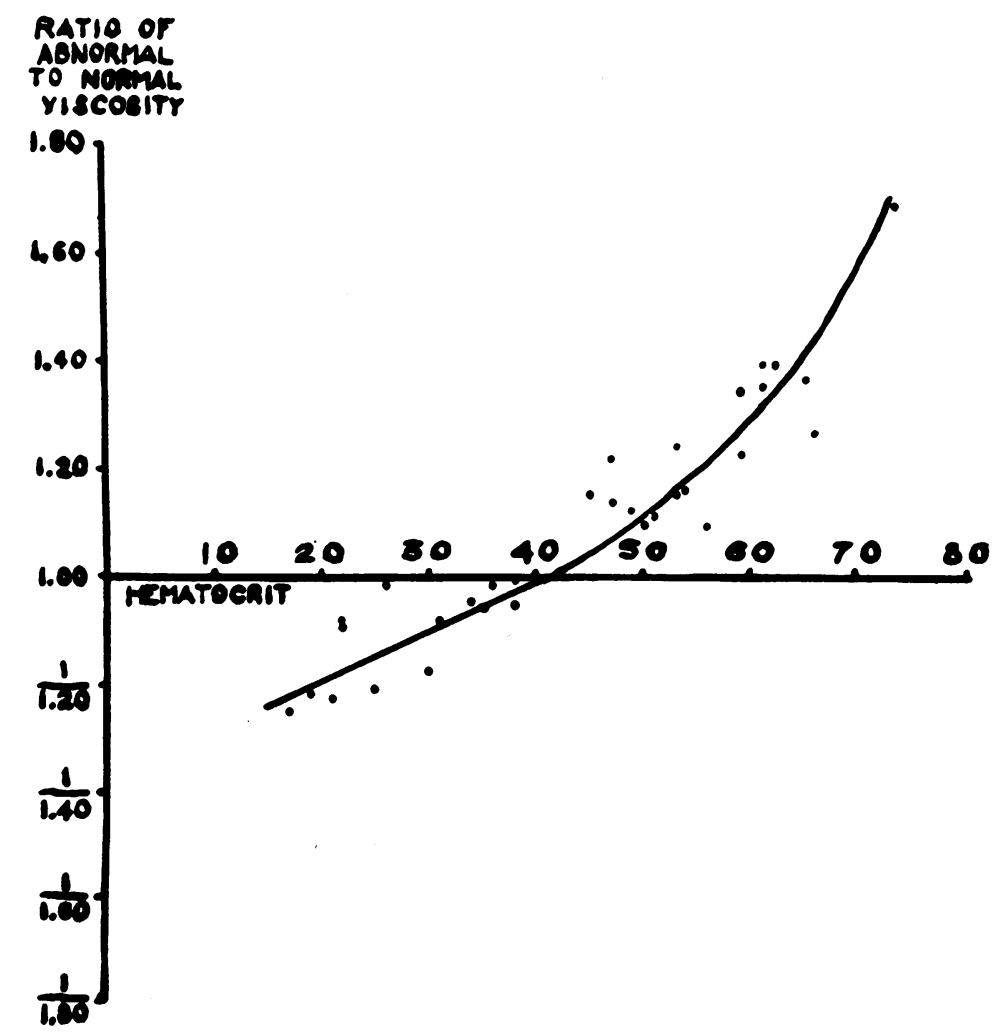

Fig. 1. The Black Dots Represent Observed Changes in Human Intravascular Viscosity with Varying Erythrocyte Concentrations in Six Patients

The curve is drawn in from Whittaker and Winton (12) making allowances for a slightly higher normal hematocrit of dogs and for the fact that flow is expressed volumetrically rather than gravimetrically. 


\section{ACKNOWLEDGMENTS}

This opportunity is taken to acknowledge with gratitude the coöperation of Drs. N. Rosenthal, F. A. Bassen, L. A. Wasserman and S. Feitelberg in these studies.

\section{BIBLIOGRAPHY}

1. Newton, Sir Isaac, Mathematical Principles of Natural Philosophy, Book II, Section IX, The circular motion of fluids. Andrew Motte Translation revised by Florian Cajori. Univ. of Calif. Press, Berkeley, Calif., 1934.

2. Einstein, A., Bermerkung zu der Abhandlung von W. R. Hess. "Beitrag zur Theorie der Viscosität heterogener Systeme.” Kolloid-Ztschrft., 1920, 27, 137.

3. Poiseuille, J. L. M., Recherches expérimentales sur le mouvement des liquides dans les tubes de très petits diamètres. Comptes Rendus hébd. des Séances de l'Acad. des Sciences, 1840, 11, 961, $1041 ; 1841,12,113$.

4. du Noüy, P. L., The viscosity of blood serum as a function of temperature. J. Gen. Physiol., 1929, 12, 363.

5. Copley, A. L., Krchma, L. C., and Whitney, M. E., Humoral rheology; viscosity studies and anomalous flow properties of human blood systems with heparin and other anticoagulants. J. Gen. Physiol., 1942, 26, 49.

6. Ostwald, W., Ueber die Geschwindigkeitsfunktion der Viskosität disperser Systeme. 1. KolloidZtschrft., 1925, 36, 99.

7. Hess, W., Ein neuer Apparat zur Bestimmung der Viskosität des Blutes. Münch. Med. Wchnschr., 1907, 54, 1590.

8. Hess, W., Reibungswiderstand des Blutes und Poiseuillesches Gesetz. Ztschr. f. klin. Med., 1910, 71, 421.

9. Green, H. D., Circulation: physical principles. Medical Physics, edited by O. Glasser. The Year Book Publishers, Inc., Chicago, Ill., 1944.

10. Hatschek, E., The Viscosity of Liquids. G. Bell and Sons, Ltd., London, 1928.

11. Jochims, J., Utber die Veränderungen der Viscosität von normalem und pathologischem Blutplasma mit der Temperatur. Arch. f. d. ges. Physiol., 1931, 227, 759.
12. Whittaker, S. R. F., and Winton, F. R., The apparent viscosity of blood flowing in the isolated hindlimb of the dog and its variation with corpuscular concentration. J. Physiol., 1933, 78, 339.

13. Bingham, E. C., and Roepke, R. R., The rheology of the blood. J. Gen. Physiol., 1944, 28, 79.

14. Fåhraeus, R., and Lindqvist, T., The viscosity of the blood in narrow capillary tubes. Am. J. Physiol., 1931, 96, 562.

15. Suter, H., Stromen des Blutes in Kapillaren. Arch. f. Kreislaufforsch., 1942, 10, 339.

16. Mendlowitz; M., Some observations on clubbed fingers. Clin. Sci., 1938, 3, 387.

17. Mendlowitz, M., The digital blood flow, arterial pressure, and vascular resistance in arterial hypertension and in coronary thrombosis. J. Clin. Invest., 1942, 21, 539.

18. Gaertner, G., Utber einen neuen Blutdruckmesser (Tonometer). Wien. klin. Wchnschr., 1899, 12, 696.

19. Mendlowitz, M., Measurements of blood flow and blood pressure in clubbed fingers. J. Clin. Invest., 1941, 20, 113.

20. Stewart, G. N., Studies on the circulation in man. Harvey Lectures, 1912-13, 86.

21. Mendlowitz, M., The specific heat of human blood. Science, 1948, 107, 97.

22. Wintrobe, M. M., Clinical Hematology. Lea and Febiger, Philadelphia, 1946.

23. Ebert, R. V., and Stead, E. A., Jr., Demonstration that the cell plasma ratio of blood contained in minute vessels is lower than that of venous blood. J. Clin. Invest., 1941, 20, 317.

24. Phillips, R. A., Yeomans, A., Dole, V. P., Farr, L. E., Van Slyke, D. D., and Hogan, D., Estimation of blood volume from change in blood specific gravity following a plasma infusion. J. Clin. Invest., 1946, 25, 261.

25. Pappenheimer, J. R., and Maes, J. P., A quantitative measure of the vasomotor tone in the hindlimb muscles of the dog. Am. J. Physiol., 1942, 137, 187.

26. Landis, E. M., Poiseuille's law and the capillary circulation. Am. J. Physiol., 1933, 103, 432.

27. Lamport, H., Improvements in calculation of renal resistance to blood flow; charts for osmotic pressure and viscosity of blood. J. Clin. Invest., 1943, 22, 461. 